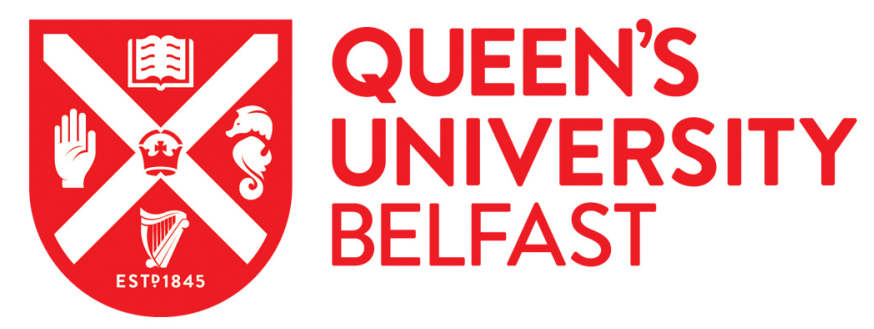

\title{
Glued-in Basalt FRP rods under combined axial force and bending moment: An experimental study
}

O'Neill, C., McPolin, D., Taylor, S., Martin, A., \& Harte, A. (2017). Glued-in Basalt FRP rods under combined axial force and bending moment: An experimental study. Composite Structures, 2-23.

https://doi.org/10.1016/j.compstruct.2017.12.029

\section{Published in:}

Composite Structures

\section{Document Version:}

Peer reviewed version

\section{Queen's University Belfast - Research Portal:}

Link to publication record in Queen's University Belfast Research Portal

\section{Publisher rights}

Copyright 2017 Elsevier.

This manuscript is distributed under a Creative Commons Attribution-NonCommercial-NoDerivs License

(https://creativecommons.org/licenses/by-nc-nd/4.0/), which permits distribution and reproduction for non-commercial purposes, provided the author and source are cited.

\section{General rights}

Copyright for the publications made accessible via the Queen's University Belfast Research Portal is retained by the author(s) and / or other copyright owners and it is a condition of accessing these publications that users recognise and abide by the legal requirements associated with these rights.

Take down policy

The Research Portal is Queen's institutional repository that provides access to Queen's research output. Every effort has been made to ensure that content in the Research Portal does not infringe any person's rights, or applicable UK laws. If you discover content in the Research Portal that you believe breaches copyright or violates any law, please contact openaccess@qub.ac.uk. 


\section{Glued-in Basalt FRP rods under combined axial force and bending moment: An experimental}

study

Caoimhe O’Neill a , Daniel McPolin ${ }^{\text {a }}$, Su E. Taylor ${ }^{\text {a }}$ and Annette M. Harte ${ }^{\text {b }}$

${ }^{a}$ Civil Engineering Research Centre, School of Planning, Architecture and Civil Engineering, Queen's University Belfast, UK, BT9 5AG

${ }^{\mathrm{b}}$ College of Engineering and Informatics, National University of Ireland Galway, Galway, Ireland coneill86@qub.ac.uk,d.mcpolin@qub.ac.uk, s.e.taylor@qub.ac.uk, annette.harte@nuigalway.ie

\section{ABSTRACT}

Glued-in rods have potential for use as moment-resisting connections in timber structures. There has been minimal research to date conducted on the performance of glued-in rods acting under both axial force and moment. The influence of increasing embedded length of the glued-in rod on the strength of the system was assessed using a pull-bending test which subjected the connection to this force combination. The longest length $(600 \mathrm{~mm})$ had a pull-out capacity $213 \%$ greater than the shortest $(80 \mathrm{~mm})$. To reduce instances of splitting in the timber end distance was varied. Optimum end distance of $42 \mathrm{~mm}\left(3.5 d_{r}\right)$ was identified with further increase having minimal impact upon overall strength.

KEYWORDS: Timber; BFRP rods; glued-in rods; connections.

\section{Introduction}

Glued-in rods (GiRs) allow hidden internal strengthening and connections which are aesthetically pleasing. They can be used in the repair of deteriorated buildings, as reinforcement of timber elements or for connections in new-build including moment-resisting corner connections.

GiRs are by no means a new technology. Research has been conducted on their use since the 1980s; however, the majority of this research has been focused on steel rods glued-in to glulam elements under purely axial loading. The stress distribution along the length of a GiR is generally considered to be uneven with stress peaks at each end of the glued length [1], [2]. Much of the research to date has 
consisted of either direct axial-only pull-out testing or finite element modelling with the models being verified with experimental data from axial-only pull-out tests [3]. However in service a GiR in a moment resisting connection or at mid-span in a spliced beam will be subject to a combination of axial and bending forces rather than exclusively axial force as researched by [4], [5]. A further understanding of the performance of GiRs under this loading combination must be attained to better predict their behaviour in service. Some work that has been carried out in this area to date has included [6], [7] who performed frame testing where timber beams were joined to a steel plate or connector using GiR technology however their method relies on the ductility of the steel used which is a feature BFRP rods do not have.

An experimental set-up was developed to study the behaviour of the GiR system under a combination of axial and bending forces. The testing method allowed controlled adjustment of variables to assess their influence on performance of the system. The materials used in this study were varied from the traditional steel rods glued-in to glulam with instead Basalt Fibre Reinforced Polymer (BFRP) rods being glued-in to sections of C16 Sitka Spruce. A summary of the benefits of using BFRP as an alternative to steel can be found in [8]. Embedded length and edge distance were identified as the most potentially influential variables on GiR performance, as such these were the key variables explored in this research.

Pull-out testing was used to assess the performance of glued-in BFRP rods under a combined axial and bending load. Performance was appraised by considering both the joint performance in terms of strength, failure mode and deflection and the nature of the stress distribution along the joint interface. This was achieved by altering both embedded length and edge distance in a controlled manner and monitoring the effect this had on performance. Joint performance was determined by measuring force, deflections and strain as well as observing behaviour during loading and failure mode.

\section{Materials and methods}

\subsection{Materials}

Class C16 Irish Sitka Spruce (Picea sitchensis), sourced from Balcas Sawmill, Co. Fermanagh, with a size of $75 \mathrm{~mm} \times 225 \mathrm{~mm}$ sawn section was used. The C16 classification shows that, at a moisture content of $12 \%$, the timber has a $5^{\text {th }}$ percentile bending strength of $16 \mathrm{~N} / \mathrm{mm}^{2}$ and a density of $370 \mathrm{~kg} / \mathrm{m}^{3}$. Material testing on a random selection of specimens established these strengths with 20 specimens being tested for 
each property a summary of which are presented in Table 1. Modulus of elasticity, bending strength, compressive strength were carried out as per the recommendations outlined in BS EN 408 [9] wile shear

54 strength and shear modulus was measured using a smaller scale test than that prescribed in the standards. Where testing was not carried out under the reference conditions outlined in EN 408 correction factors were employed to standardise the results. Moisture content of the timber in each test was monitored using a handheld moisture metre. Characteristic values, 5-percentile, were calculated using the parametric calculation methods outlined in BS EN 14358 [10] since sample sizes for the determination of each property were less than or equal to $\mathrm{n}=40$.

\begin{tabular}{|c|c|c|c|}
\hline & & $\begin{array}{c}\text { BS EN } 338 \\
\text { (C16 Graded) }\end{array}$ & Experimental \\
\hline $\begin{array}{c}\text { Bending } \\
\text { strength }\left(\mathrm{N} / \mathbf{m m}^{2}\right)\end{array}$ & $f_{m, k}$ & 16.0 & 18.4 \\
\hline $\begin{array}{c}\text { Shear } \\
\text { strength }\left(\mathrm{N} / \mathbf{m m}^{2}\right)\end{array}$ & $f_{v, k}$ & 3.2 & 8.7 \\
\hline $\begin{array}{c}\text { Compression parallel } \\
\left(\mathbf{N} / \mathbf{m m}^{2}\right)\end{array}$ & $f_{c, 0, k}$ & 17.0 & 16.3 \\
\hline $\begin{array}{l}\text { Compression perpendicular } \\
\left(\mathbf{N} / \mathbf{m m}^{2}\right)\end{array}$ & $f_{c, 90, k}$ & 2.2 & 2.5 \\
\hline $\begin{array}{c}\text { Mean modulus } \\
\text { of elasticity }\left(\mathbf{k N} / \mathbf{m m}^{2}\right)\end{array}$ & $E_{0, \text { mean }}$ & 8.0 & 9.0 \\
\hline $\begin{array}{c}\text { Mean shear } \\
\text { modulus }\left(\mathbf{k N} / \mathbf{m m}^{2}\right)\end{array}$ & $G_{\text {mean }}$ & 0.5 & - \\
\hline Density $\left(\mathrm{kg} / \mathrm{m}^{3}\right)$ & $P_{k}$ & 310 & 357 \\
\hline
\end{tabular}

61 Basalt Fibre Reinforced Polymer (BFRP) rods of $12 \mathrm{~mm}$ diameter were used throughout this experimental programme. These rods were found to have a tensile strength of $920 \mathrm{~N} / \mathrm{mm}^{2}$ under a loading rate of $630.2 \mathrm{kN} / \mathrm{s}$ and a modulus of elasticity of $54 \mathrm{kN} / \mathrm{mm}^{2}$ [11]. Unlike steel or some other FRPs, no extensive cleaning of the rods was required prior to bonding as they are sand-coated which provides a good surface for adhesion.

66 A two-part Rotafix structural epoxy adhesive was used to glue-in the BFRP rods. This adhesive is thixotropic (it only flows under shear) so is ideal for applications such as overhead beam repair and 
jointing overhead. The epoxy used had a bond strength of 6-10 N/mm² dependant on the adherends and preparation of the bonding surfaces. Compressive strength of the adhesive was at least $60 \mathrm{~N} / \mathrm{mm}^{2}$ and it had a tensile strength of $38 \mathrm{~N} / \mathrm{mm}^{2}$ and modulus of elasticity of [12].

\subsection{Pull-out test method}

72

Pull-out capacity is used as a measure of the strength of a GiR. Assessment of pull-out capacity of a rod glued-in to timber can be achieved with various test configurations as seen in the literature [13], [8]. In a moment resisting timber connection, such as an eave connection in a portal frame structure, it is highly likely that some bending forces would also be acting on the GiR rather than axial-only as in the commonly used pull-out set-ups. To include these bending effects a pull-bending set-up should be used. This involves the use of a hinge apparatus based on the concrete beam test proposed by RILEM 1982 (RILEM TC, 1994). The system allows bending strength of the GiR connection to be evaluated by removing the timber in the section being loaded so that the only resistance is from the GiR connecting the two timber elements. It is this system that was used in this research to establish pull-out capacity. The pull-bending test set-up that was used is illustrated in Figure 1 with critical dimensions detailed on the figure: distance from loading head to inner support $l_{l}$, internal lever arm $z$, edge distance $a$, height of beam $h$, embedded length $l_{b}$, span $L$. In all specimens the distance between the inner supports, $2 l_{l}=$ $150 \mathrm{~mm}$, height of the beam, $h=225 \mathrm{~mm}$ and span, $L=1600 \mathrm{~mm}$. Stress in the rod was monitored by means of an electrical resistance strain (ERS) gauge placed at mid-span on the exposed BFRP rod on each sample.

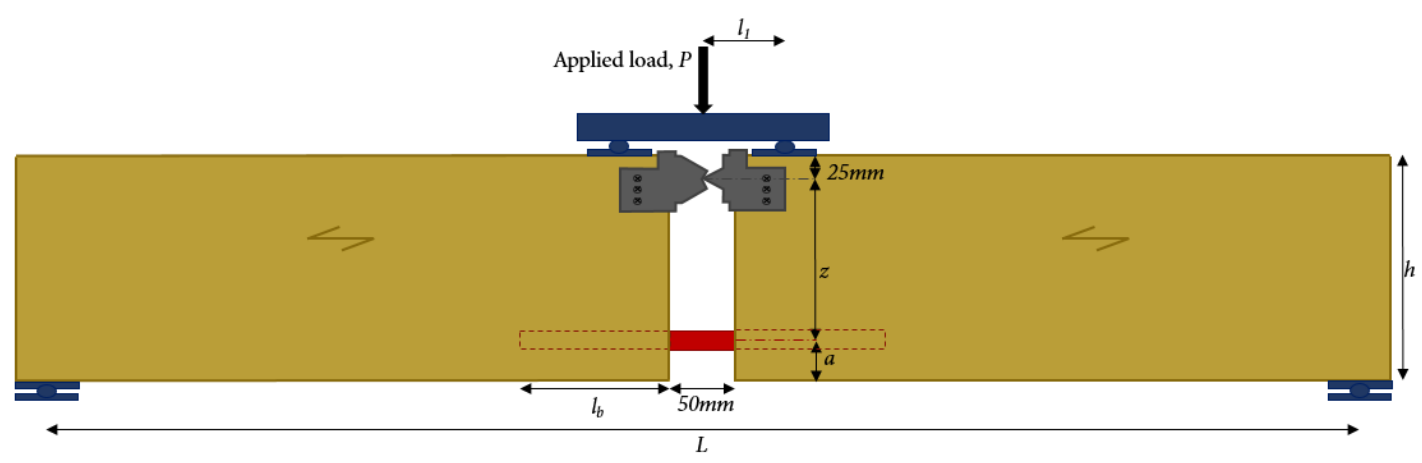

Figure 1: Pull-bending test set-up 
All specimens were tested under ambient conditions of temperature and humidity. Moisture content of each specimen was recorded at the time of testing using a handheld moisture meter, moisture content was typically $10.1 \%$. Due to the anisotropic nature of timber, to enable comparison between specimen sets rods were embedded parallel-to the grain in all specimens.

Timber beams were cut to length and an auger drill bit was used to drill holes of $16 \mathrm{~mm}$ diameter, thus producing a glueline thickness of $2 \mathrm{~mm}$ all around the $12 \mathrm{~mm}$ diameter rods. This was considered the optimum value for performance based on the work by Harvey \& Ansell (2000) amongst others. Guide blocks were used to ensure the holes were drilled accurately. Rods were cut to length using a grinder with a cutting blade. No surface preparation was required of the rods. Rods were sanded locally to the position of the ERS gauges. The gauges were then glued directly on to the rod. The surface of the timber around the drilled hole was sealed with wax to ensure that any glue overspill would not penetrate the sample and result in an artificial increase in strength around the hole. Holes were then 2/3rds filled with adhesive and the rods twisted into place allowing any trapped air to be expelled and ensuring the glue fully coated the surface of the rods, this method was found in preliminary tests to provide full coating of the rods. When glue emerged from the open end the rods were deemed to be sufficiently coated. A temporary support was used to hold the specimen in place to maintain the $2 \mathrm{~mm}$ glueline all around the rod whilst drying. When the glue had hardened the steel hinges at the top and strain gauges at mid-span on the exposed rod were fitted. The specimens were then left until the glue had a minimum of 7 days to cure fully before testing.

\section{Embedded length, $l_{b}$}

Minimum embedded length was chosen based on the guidelines proposed for inclusion in the preliminary versions of Eurocode 5 [16] where the recommendation was that minimum embedded length should be no less than the greater of $0.4 d_{r}{ }^{2}$ or $8 d_{r}$. In the case of a $12 \mathrm{~mm}$ diameter rod this gives a minimum embedded length of $96 \mathrm{~mm}$. Embedded length, $l_{b}=80 \mathrm{~mm}$ was chosen to explore the performance of an embedded length lesser than that proposed. Embedded length was increased in steps of 50mm $\left(4.167 d_{r}\right)$. Initially the final embedded length was chosen as $280 \mathrm{~mm}\left(23.3 d_{r}\right)$ based on findings in the literature where a plateau in strength was expected to occur around $240 \mathrm{~mm}\left(15 d_{h}=20 d_{r}\right)$ where the use of Basalt 

observed and thus the maximum embedded length was extended to $600 \mathrm{~mm}\left(50 d_{r}\right)$. Table 2 details the embedded lengths investigated.

Table 2: Specimens investigating embedded length, $l_{b}$

\begin{tabular}{c|ccc} 
Set ID & Embedded length $(\mathbf{m m})$ & Embedded length $\left(\boldsymbol{d}_{\boldsymbol{r}}\right)$ & Embedded length $\left(\boldsymbol{d}_{\boldsymbol{h}}\right)$ \\
\hline LB_80 & 80 & 6.67 & 5.000 \\
LB_130 & 130 & 10.83 & 8.125 \\
LB_180 & 180 & 15.00 & 11.250 \\
LB_230 & 230 & 19.16 & 14.375 \\
LB_280 & 280 & 23.33 & 17.500 \\
LB_330 & 330 & 27.50 & 20.625 \\
LB_380 & 380 & 31.67 & 23.750 \\
LB_600 & 600 & 50.00 & 37.500
\end{tabular}

Edge distance, $a$

Edge distance, $a$, was set at $30 \mathrm{~mm}\left(2.5 d_{r}\right)$ for the initial testing campaign where embedded length was being investigated. This edge distance was chosen based on the recommendation proposed in prEN1995 that $a_{\min }=2.5 d_{r}$. It was discovered through a test series that splitting of the tensile face of the timber occurred because of the build-up of stresses approaching failure. In an attempt to alleviate this problem, edge distance was increased. However, by increasing edge distance, $a$, the effective lever arm, $z$, in the system will decrease as per Figure 1. In moment resisting connections, the greatest moment resistance is normally achieved by maximising the lever arm. Thus, the overall maximum capacity of a moment resisting connection will be reached by finding the balance between maximum possible lever arm without causing splitting of the timber.

Edge distance was increased by steps of one bar diameter $(12 \mathrm{~mm})$ up to a maximum of $a=66 \mathrm{~mm}\left(5.5 d_{r}\right)$. An additional edge distance of $a=112.5 \mathrm{~mm}$, corresponding to half the beam depth was investigated although in reality this edge distance would not be possible since the spacing required would not allow for the use of multiple rods. A fixed embedded length, $l_{b}=280 \mathrm{~mm}\left(23.3 d_{r}\right)$ was chosen while edge distance was being varied since this was expected to give maximum performance. Table 3 below details the edge distances investigated. 


\begin{tabular}{c|cc} 
Set ID & Edge distance $\mathbf{( m m )}$ & Edge distance $\left(\boldsymbol{d}_{\boldsymbol{r}}\right)$ \\
\hline A_30 & 30.0 & 2.5 \\
A_42 & 42.0 & 3.5 \\
A_54 & 54.0 & 4.5 \\
A_66 & 66.0 & 5.5 \\
A_112.5 & 112.5 & 9.4
\end{tabular}

\subsection{Test procedure}

147 Samples were loaded at a rate of $0.015 \mathrm{~mm} / \mathrm{s}$ to ultimate failure using a calibrated $600 \mathrm{kN}$ capacity 148 hydraulic actuator. Failure load and mode of failure were recorded when the sample could not take any 149 additional load. Deflection at mid-span and net horizontal movement of the bar as the sample was loaded was recorded with data acquisition connected to the transducer. Each test was repeated with nine specimens due to the high variability of the timber used.

\section{Results and Discussion}

Performance of the GiRs was assessed in terms of failure mode and ultimate strength. The effect of increasing embedded length was explored, as was the effect of increasing the edge distance on both failure strength and failure mode.

\subsection{Failure modes}

Failure was deemed to have occurred when the specimen could not withstand further loading. All specimens failed in a sudden, brittle manner. Two primary failure modes were identified and are shown in

Figure 2: a timber plug pull-out indicative of shear failure in the timber and a 'clean' pull-out signifying a failure of the rod/adhesive interface. Another failure mode which was observed mainly in specimens with the longest embedded length, $l_{b}=600 \mathrm{~mm}$, was failure of the timber either by crushing of the timber under the loading points and steel hinge or a failure of the timber. In these specimens the timber failed before 


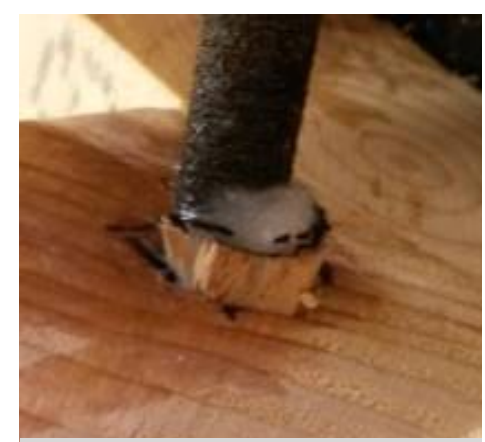

a) Shear pull-out in the timber

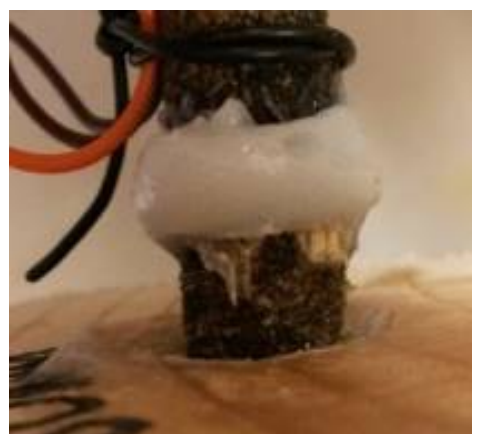

b) Failure in rod/adhesive interface

Figure 2: Two primary failure modes observed

the GiR, as such, the strength presented is taken from the load at which the timber failed however it is known that the GiR is stronger than this.

Table 4 and Table 5 detail the failure modes observed in each set of specimens tested. In the GiR connections tested in this research the weakest element in the connection is the timber since the load required to fail the brittle BFRP rods is very large. It was therefore expected that failure will occur in the timber element, close to the adhesive/timber interface. Indeed, the most prevalent failure mode observed was a pull-out failure in shear of the timber with a total of $75 \%$ of all samples failing in this manner. Rod/adhesive failure occurred either when to the sand coating on the rod had not adhered sufficiently well to the adhesive or when the sand coating detached suddenly from the rod surface. The BFRP rod never failed as the force required for the rupture of the rod was never reached. Splitting was evident in $24 \%$ of all specimens. Splitting occurred as a consequence of the build-up of stresses approaching failure, the instances of splitting are noted in Table 4 and Table 5. When splitting of the timber occurred, the length of the split was often equal to the embedded length of the rod, this was also found experimentally by [18].

Table 4: Summary of failure modes observed with varying $l_{b}$

\begin{tabular}{|c|c|c|c|c|}
\hline \multirow[b]{2}{*}{ Set ID } & \multicolumn{3}{|c|}{ Major failure mode, no. (\%) } & \multirow[b]{2}{*}{$\begin{array}{c}\text { Specimens with } \\
\text { splitting } \\
\end{array}$} \\
\hline & Shear pull-out & $\begin{array}{c}\text { Rod/Adhesive } \\
\text { pull-out }\end{array}$ & Timber failure & \\
\hline LB_80 & $7(78 \%)$ & $2(22 \%)$ & 0 & $1(11 \%)$ \\
\hline LB_130 & $8(89 \%)$ & $1(11 \%)$ & 0 & $3(33 \%)$ \\
\hline
\end{tabular}




\begin{tabular}{l|lcc|l} 
LB_180 & $6(67 \%)$ & $3(33 \%)$ & 0 & $1(11 \%)$ \\
LB_230 & $5(56 \%)$ & $4(44 \%)$ & 0 & $1(11 \%)$ \\
LB_280 & $7(78 \%)$ & $2(22 \%)$ & 0 & $4(44 \%)$ \\
LB_330 & $7(78 \%)$ & $2(22 \%)$ & 0 & $5(56 \%)$ \\
LB_380 & $8(89 \%)$ & $1(11 \%)$ & 0 & $2(22 \%)$ \\
LB_600 & $4(44 \%)$ & 0 & $5(56 \%)$ & $4(44 \%)$
\end{tabular}

Table 5: Summary of failure modes observed with varying $a$

\begin{tabular}{c|ccc|c} 
& \multicolumn{2}{|c|}{ Major failure mode (Number of specimens) } & Specimens with \\
Set ID & Shear pull-out & $\begin{array}{c}\text { Rod/Adhesive } \\
\text { pull-out }\end{array}$ & Timber failure & splitting \\
\hline A_30 & $7(78 \%)$ & $2(22 \%)$ & 0 & $4(44 \%)$ \\
A_42 & $7(78 \%)$ & $1(11 \%)$ & $1(11 \%)$ & $1(11 \%)$ \\
A_54 & $8(89 \%)$ & $1(11 \%)$ & 0 & 0 \\
A_66 & $6(67 \%)$ & $3(33 \%)$ & 0 & $1(11 \%)$ \\
A_112.5 & $8(89 \%)$ & $1(11 \%)$ & 0 & $4(44 \%)$
\end{tabular}

The average strength of specimens that did not split was compared to the average strength of those that did split. It was clear that when splitting occurred a lower average failure strength was reached. This decrease is due to the specimen being weakened by the split in the cross-section of the timber and thus the having a lower resistance to the applied load.

\subsection{Strength}

Failure strength was deemed to be the peak strength reached by specimens. The failure strength could be calculated by either of two methods: By considering the applied load and the geometry of the test specimen the force in the GiR can be calculated by balancing forces in the system; From strain measurements taken at mid-span along the GiR the stress in the GiR is calculated using the modulus of elasticity of the rod material, this is then translated to a force in the rod by considering the cross-sectional area of the rod.

A linear relationship between measured strain at mid-span and applied force form the testing machine was observed that allowed strength of the GiR to be calculated. The strain values obtained were used in the calculation of force in the rod at the mid-span as described above. At failure, strain dropped off 
194 immediately. ERS gauges in most specimens were destroyed by the explosive type failure therefore

195 readings beyond the point of failure were not possible.

196 In most specimens, the value of strength calculated by geometry was slightly lower than that from strain

197 readings. This is thought to be due to small discrepancies in dimensions of the sawn timber specimens.

198 The strength values presented in this paper are those derived from geometry since in a few specimens the

199 ERS gauge at mid-span failed before peak loading was reached therefore readings were incomplete, also

200 there was much larger variation in the strengths determined from measured strain.

201 Table 6 summarises mean failure strengths for each set calculated from the peak loads reached over an

202

203

204

205

Table 6: Summary of failure strengths for varying embedded length

\begin{tabular}{c|cccccccc} 
& $\mathbf{L B}_{-}$ & $\mathbf{L B}_{-}$ & $\mathbf{L B}_{-}$ & $\mathbf{L B}_{-}$ & $\mathbf{L B}_{-}$ & $\mathbf{L B}_{-}$ & $\mathbf{L B}_{-}$ & $\mathbf{L B}_{-}$ \\
\hline $\begin{array}{c}\text { Mean failure } \\
\text { strength, } \boldsymbol{P}_{\mathbf{u}}(\mathbf{k N})\end{array}$ & 29.71 & 42.60 & 59.72 & 64.16 & 74.57 & 79.74 & 75.79 & 93.12 \\
$\begin{array}{c}\text { Standard } \\
\text { deviation (kN) }\end{array}$ & 7.70 & 8.73 & 6.98 & 11.05 & 13.71 & 8.31 & 9.24 & 13.10 \\
$\begin{array}{c}\text { Coefficient of } \\
\text { variation }\end{array}$ & 0.55 & 0.44 & 0.25 & 0.37 & 0.39 & 0.22 & 0.26 & 0.30
\end{tabular}

\section{Influence of embedded length}


207 A clear increase in pull-out strength was observed with an increase in embedded length. Figure 3[CO1]

208 shows this relationship. An increase in pull-out capacity of $213 \%$ was observed between the shortest 209 embedded length of $80 \mathrm{~mm}$ and the longest length of $600 \mathrm{~mm}$. It was expected that this trend would be 210 found since the larger interface area with each increase in embedded length provides additional resistance 211 to the applied loading. This is in line with research by [2], [15], [19] amongst others. However, the plateau found by [17] was not observed.

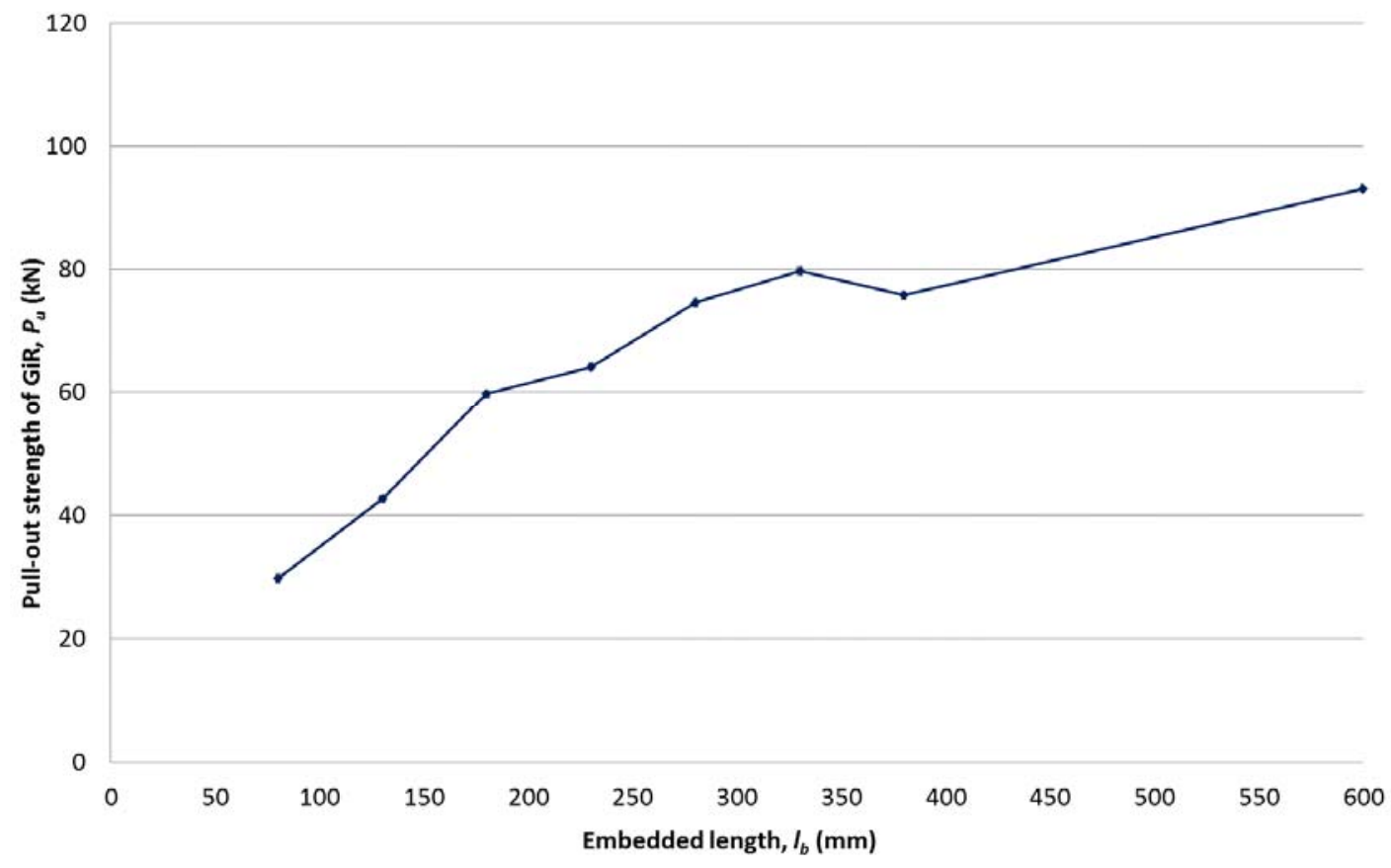

Figure 3: Pull-out strength with increasing embedded length

Figure 4: Average shear stress at timber/adhesive interface at peak load

213 The rate of increase of pull-out strength decreased at the higher embedded lengths. This suggested that 214 strength was approaching a plateau as stress capacities of the connection were being reached and that 215 perhaps the entire glued length was not resisting the applied loading effectively. It is believed that the bending effects present in this investigation contribute to this finding, similar to the findings of [20]. the shortest embedded length to almost half the specimens experiencing a compressive failure of the timber in longest embedded length, this is detailed in Table 4. This change in failure mode was perhaps a 
result of shear stress at the timber/adhesive interface decreasing with increasing embedded length.

221 Average shear stress at peak load was calculated by dividing the peak strength by the surface area of the 222 timber/adhesive interface. The relationship between average timber/adhesive shear stress at peak load and embedded length is detailed in Figure 4. Shear stress at the timber/adhesive interface exhibited a general decrease with increasing embedded length. This had been anticipated since the longer embedded length results in a larger interface area to resist applied loading.

\section{Comparison with design guidelines}

Embedded length is one of the recurring variables that appear in most published design equations. A comprehensive review of the most commonly used design equations is presented in [21]. Comparing the experimental data obtained in this research to the three most used design guidelines, as illustrated in Figure 5 , it can be seen that the data follows the same trend as both the German timber design codes, DIN 1052 (DIN 2008) and Riberholt's design equations [23]. The experimental strengths are significantly stronger than both the DIN and Riberholt predictions however this is to be expected since the guidelines are designed to give a safe prediction of strength. The GIROD prediction gives a completely linear behaviour. While this is conservative at shorter embedded lengths compared to the experimentally derived data, beyond an embedded length of $330 \mathrm{~mm}$ the design prediction is significantly higher than the

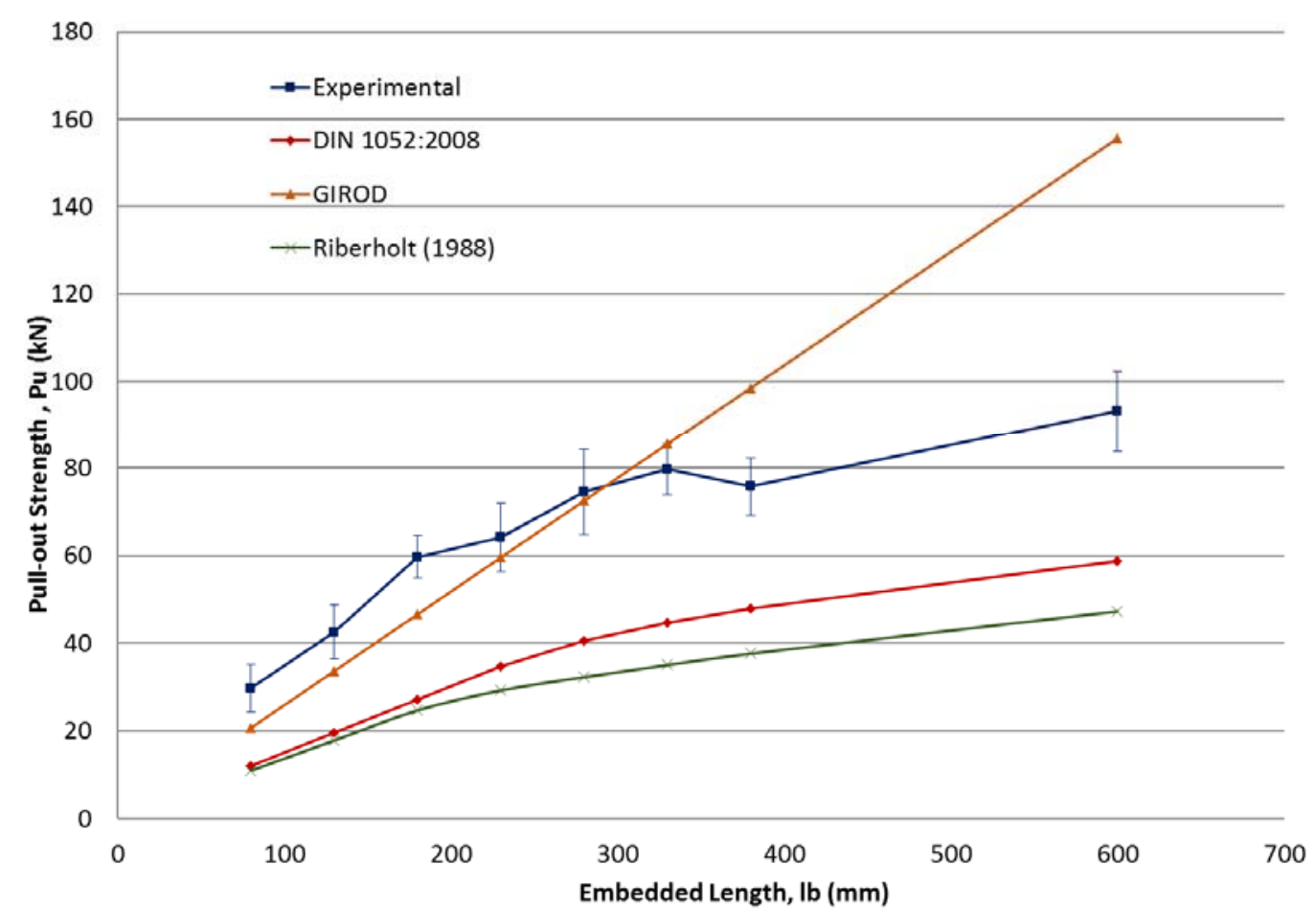

Figure 5: Comparison of experimental results with published formulae 
experimentally obtained strengths and therefore unsafe.

An embedded length of $280 \mathrm{~mm}$ was identified as the optimum embedded length. Although strength continued to increase at embedded lengths beyond this value, the rate of increase was lesser than previous to this point. In addition, the capacity of $280 \mathrm{~mm}$ embedded rods is sufficient to withstand the normal loading expected to be carried by these GiRs.

\section{Influence of edge distance}

Following a relatively high instance of splitting among the first phase of pull-out testing, particularly in the optimum embedded length set LB_280, a second testing phase was established to determine the effect of splitting by increasing edge distance and whether this increase in edge distance would have any effect on strength or failure mode of specimens. The results of this phase are presented in Table 7.

249
Failure mode [No. specimens (Strength)]

\begin{tabular}{c|c|c|cc|c}
$\begin{array}{c}\text { Specimen } \\
\text { set }\end{array}$ & $\begin{array}{c}\text { Edge } \\
\text { dist. }\end{array}$ & $\begin{array}{c}\text { Overall pull-out } \\
\text { strength of GiR } \\
\text { (kN) }\end{array}$ & $\begin{array}{c}\text { Pull-out with } \\
\text { timber }\end{array}$ & Rod/Adhesive & $\begin{array}{c}\text { Splitting } \\
\text { present }\end{array}$ \\
\hline A_30 & $2.5 d$ & 74.6 & $7(72.6 \mathrm{kN})$ & $2(81.6 \mathrm{kN})$ & $4(66.9 \mathrm{kN})$ \\
A_42 & $3.5 d$ & 75.4 & $8(73.8 \mathrm{kN})$ & $1(88.8 \mathrm{kN})$ & $1(77.8 \mathrm{kN})$ \\
A_54 & $4.5 d$ & 58.7 & $8(58.4 \mathrm{kN})$ & $1(61.1 \mathrm{kN})$ & 0 \\
A_66 & $5.5 d$ & 62.1 & $6(57.4 \mathrm{kN})$ & $3(71.4 \mathrm{kN})$ & $1(56.1 \mathrm{kN})$ \\
A_112.5 & $9.375 d$ & 72.9 & $8(72.9 \mathrm{kN})$ & $1(60.1 \mathrm{kN})$ & $3(69.7 \mathrm{kN})$
\end{tabular}
Failure strengths were calculated geometrically as per the same method used for the first phase of testing. Average pull-out strength across all specimens in this phase was $68.75 \mathrm{kN}$ with a standard deviation of $6.95 \mathrm{kN}$, corresponding to a coefficient of variation of 0.101 . This was comparable to the optimum specimen set identified in the first phase of testing (LB_280) which had slightly higher average strength of $74.6 \mathrm{kN}$ but with more variation, having a standard deviation of $12.9 \mathrm{kN}$.

A drop in average strength was seen where $a=4.5 d$ and $a=5.5 d$ with strengths where $a=4.5 d$ varying from the mean by over one standard deviation. The specimens in these sets were examined in case of any obvious defects such as large knots or pre-existing cracks but none were present. Several samples were then taken from these specimens to inspect the strength of the timber however again there was no obvious 
correlation between the lower strength specimens and strength of the timber. Following these considerations it was deemed appropriate to present the full complement of results.

It appears that failure mode had no definite influence upon the failure strength with specimens that failed by a shear pull-out of the timber having an average failure strength of $67 \mathrm{kN}$ and those that exhibited failure between the rod and adhesive failing within one standard deviation at a slightly higher average of $72 \mathrm{kN}$.

As detailed in Table 7, many specimens with the minimum edge distance exhibited splitting. Splitting was significantly reduced with increasing edge distance with no splitting occurring where $a=4.5 d$ or $a=5.5 d$. Splitting reoccurred in the last specimen set where edge distance was at maximum, $a=112.5 d$. When comparing specimens where splitting did occur to those that did not experience any splitting it was evident that splitting resulted in a lower failure strength with an average drop in strength of almost $8 \%$. This finding is contrary to the findings of [2] who claimed that splitting had no influence on the overall strength of the GiR. However the previous research used an axial-only pull-out test whilst the GiRs in this research are under a combination of axial load and bending force and so may behave in a different manner.

In the case of the research presented in this paper stresses induced by the bending element of the test setup result in splitting, [24] advocate that splitting occurs because of non-axial loading. Like [2], [24] reiterate that splitting is not a particular failure mode in itself but rather a symptom of the build-up of stresses perpendicular to the grain.

The location of the split on the specimen varied from the smallest to largest edge distance. It was observed that splitting moved from the tension face or both tension face and the side faces in A_30 and A_42 to along the side faces exclusively in the last A_112.5. This happened because of the build-up of stresses seeking the shortest route to dissipate. Considering the stress in the system at maximum load, where $a=2.5 d$ the stress at the rod position was $\tau=1.62 \mathrm{~N} / \mathrm{mm}^{2}$. With the movement of the rod further in to the specimen this increased with a failure stress at the rod position of $\tau=6.34 \mathrm{~N} / \mathrm{mm}^{2}$ when $a=9.375 d$ this was approaching the shear strength of the timber $f_{\mathrm{v}}=8.7 \mathrm{~N} / \mathrm{mm}^{2}$. With the lower edge distances, any 
splitting was more likely to happen on the tension face as in this case the split is following the grain of the timber.

A significant effect on performance of the specimen was seen in assessing the moment capacity of the specimens. Moment capacity was not used as a measure of performance in the first phase of testing since edge distance remained constant. However, in this phase moment capacity is perhaps a more important measure of performance than strength of the section alone. As edge distance increased the distance between the applied load and the GiR resisting this loading was reduced. Thus, moment capacity of the section decreased with increasing edge distance since moment capacity is a function of the force and lever arm. Theoretically, a linear relationship is expected however it can be seen in Figure 6 that this was not achieved experimentally. The effect of the change in lever arm and the resulting moment capacity is much more significant than any effect edge distance has on failure mode or pull-out strength of the rod, thus it could be argued that the change in failure mode becomes irrelevant.

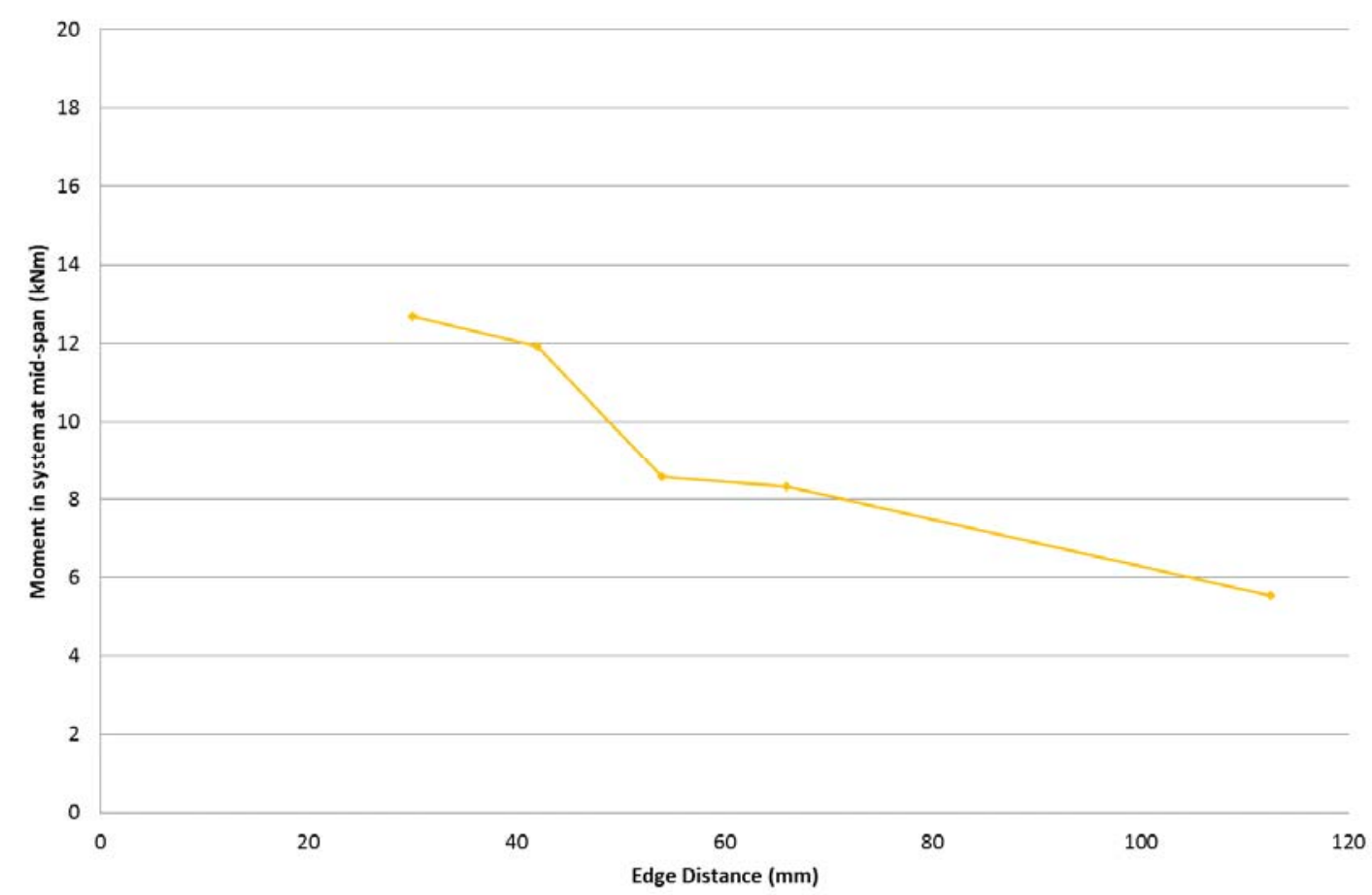

Figure 6: Moment capacity of section with increasing edge distance (Experimental results for specimens A_30 to A_112.5) 
In service, a multiple number of rods may be required to attain the necessary moment resistance. For

297 instance, from Figure 6 it can be reasoned that to withstand an applied moment of $24 \mathrm{kNm}$ either three 298 rods with an edge distance of $66 \mathrm{~mm}$ or two rods with an edge distance of $30 \mathrm{~mm}$ may be used. Group effects may then come in to play with multiple rods therefore spacing between the rods must be carefully considered. Taking this in to account 3.5 $d_{r}$ (A_42) was identified as an optimum value for edge distance. At this edge distance, splitting was greatly reduced while strength was maintained. Although it has been evidenced in this work that there remains a chance that splitting may still occur at $3.5 d_{r}$, this edge distance would allow a greater range of spacing options in cases where multiple rods are to be used when compared to the other edge distances studied herein.

\subsection{Deflections}

Deflection was recorded at each load point. In all specimens an initial increase of mid-span deflection at low load was observed. This was perhaps a settling deflection due to the hinges on the test set up having a few millimetres of movement before they connected. The load-deflection profile for a typical specimen had a linear section after this initial settlement deflection which allowed calculation of the stiffness of the system. Where there was a sudden change in deflection this was a result of cracks forming in the specimen.

\section{With varying embedded length}

Figure 7 displays the relationship between load-deflection and increasing embedded length. The values given are an average deflection over the nine specimens tested in this set. It can be observed that there is no distinct correlation between increasing embedded length and stiffness in the system. This is an area that has not been reported on widely in the literature given that the majority of previous research was conducted in axial-only pull-out test setups. Where a pull-bending test was used in the literature loaddeflection of the system was not recorded (Sena-Cruz et al. 2012). 


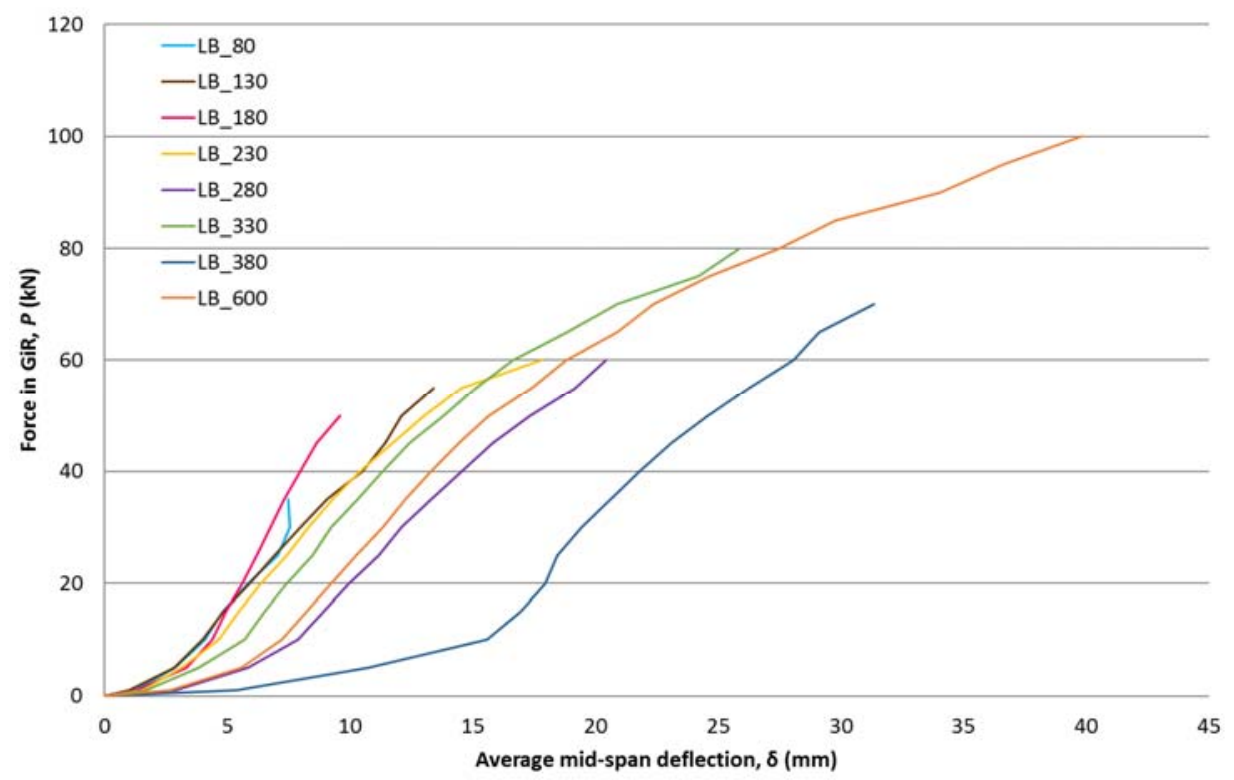

Figure 7: Load-deflection with increasing embedded length

320 A definite increase in stiffness was seen with increasing edge distance as illustrated in Figure 8. Stiffness

321 increased from 0.198 in the smallest edge distance to 0.342 in the largest embedded length.

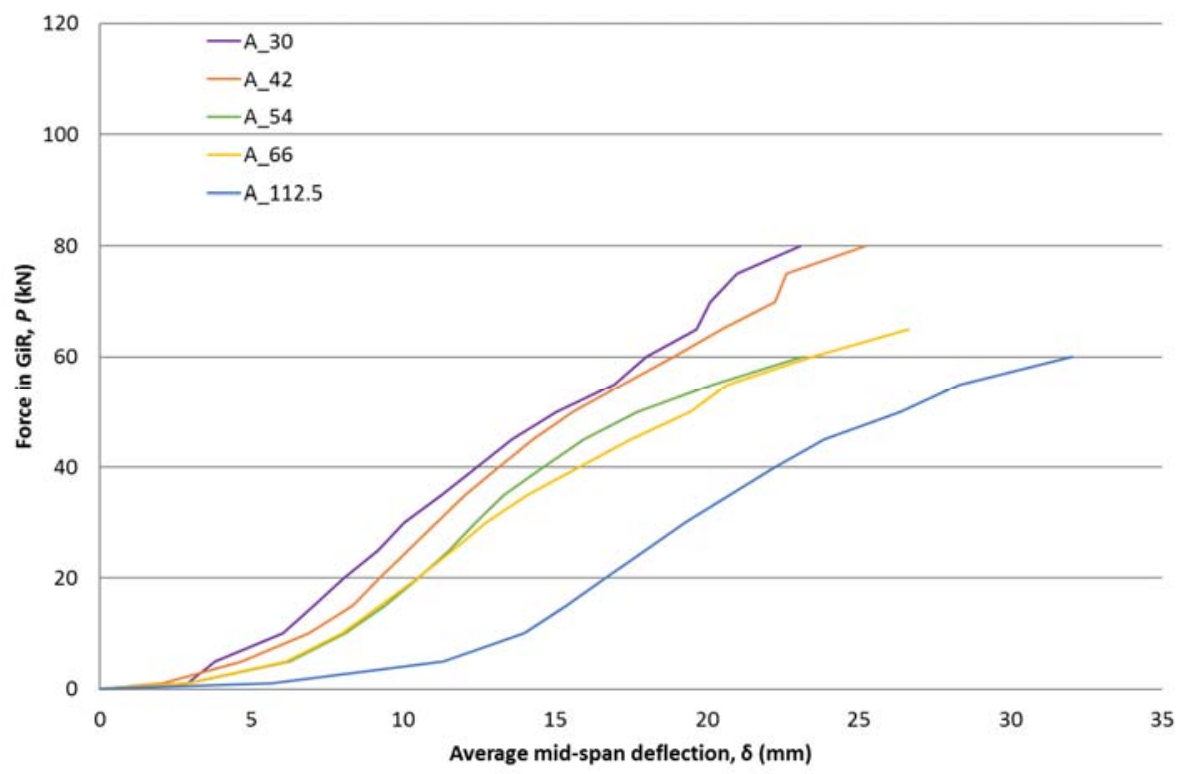

Figure 8: Load-deflection with increasing edge distance 
323 Slippage (lateral movement) of the rod was recorded at each load point via LVDTs that were mounted on 324 the timber and rested on a clamp that was fixed at mid-span on the rod. Slippage was corrected for the elongation of the rod in each case. In most specimens slippage was seen to undergo some initial settlement after which a linear increase in slippage with increasing load was observed until a sudden increase at failure corresponding to the pull-out of the rod.

\section{With varying embedded length}

329

Slippage of the failure side was analysed for all embedded lengths and the linear portion of the load-slip curve was used to evaluate the stiffness of the system. It was evident that there was no definite correlation between increasing embedded length and stiffness despite the additional rod length providing additional resistance to loading.

The values of maximum slip at the point just before failure were considered with increasing embedded length as per Figure 9. In general an increase in slip up to the point of failure was observed with increasing embedded length. This is similar to the findings of Sena-Cruz et al. (2012) who discovered a linear relationship between loaded-end slip and increasing embedded length in pull-out tests using a

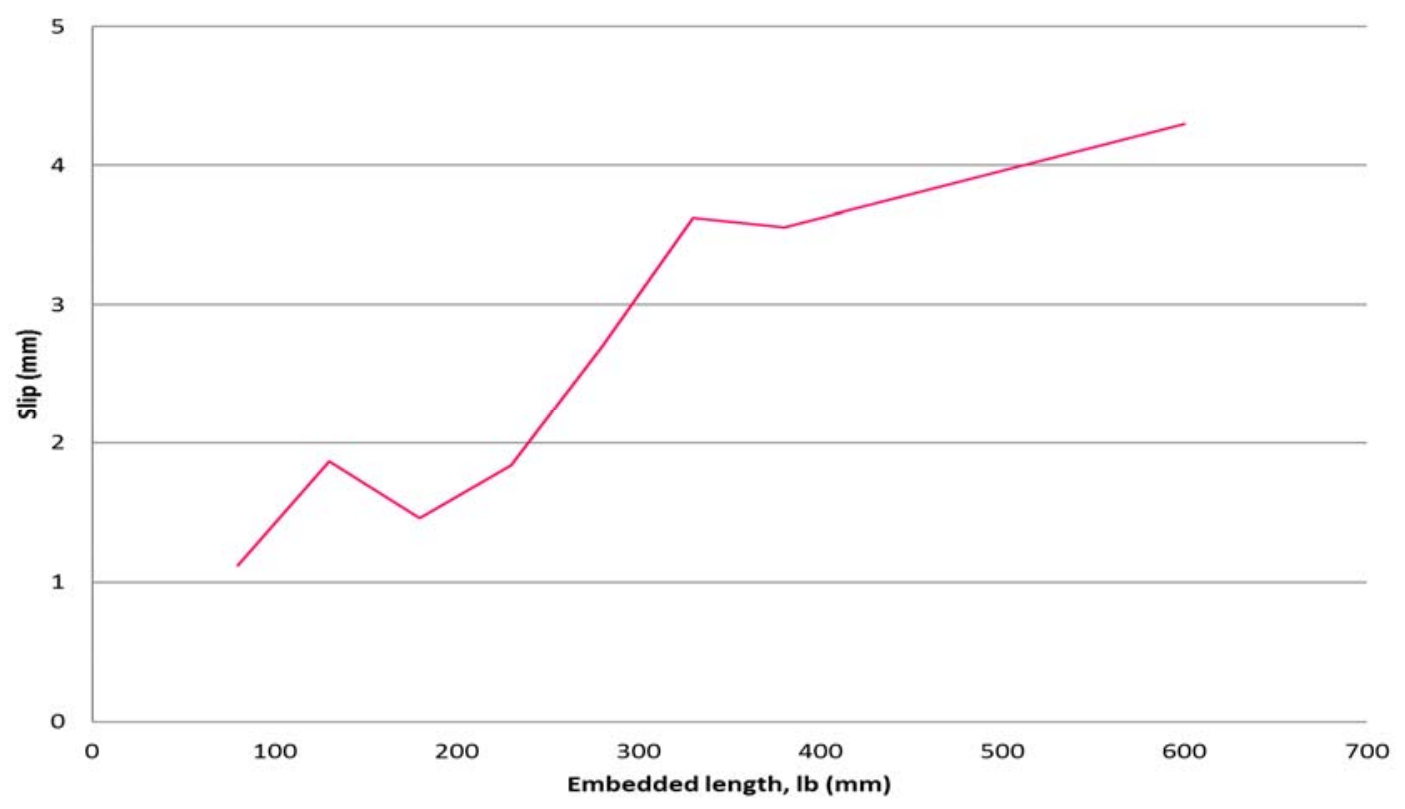

Figure 9: Slippage at point of failure with increasing embedded length (LB_80 to LB_600) 
remarked that due to the nature of the test configuration the slippage of the rod is a difficult variable to measure and as such the results have a relatively large coefficient of variation. The same concerns were experienced in this research with coefficient of variation for each embedded length ranging from 0.22 to 0.37 .

\section{Conclusions}

GiRs present an attractive alternative to traditional connections in timber structures as well as having potential for use in the repair or reinforcement of existing timber structures. Much research has been conducted on the use of GiRs over the past few decades however little is known about their behaviour under a load combination of axial and bending forces. Pull-bending tests were used as a method of assessing the performance of glued-in BFRP rods under such a loading combination and the way in which the glued length responds to this loading condition was monitored.

Embedded length is considered one of the key variables influencing the strength of GiR connections. It is seen repeatedly in previous research and can be easily altered in a laboratory environment. Some previous research has identified a peak in embedded length after which strength ceases to increase however, these experiments were limited to axial-only testing and often did not test beyond an embedded length $l_{b}=$ $350 \mathrm{~mm}$. In this experimental programme embedded lengths ranging from $l_{b}=80 \mathrm{~mm}$ to $l_{b}=600 \mathrm{~mm}$ were tested under a combination of axial and bending forces. An increase in strength was seen with increasing embedded length, with an increase in strength of approximately $10 \%$ beyond the anticipated plateau region seen by other researchers [25]. Based on the pull-out capacities and failure modes observed an optimum embedded length of $l_{b}=280 \mathrm{~mm}$ was identified and proposed for use in future applications.

In the specimens tested in this research, the timber was the weakest element in the connection. It was therefore anticipated that failure would occur in the timber element, most likely close to the timber/adhesive interface since this is where stress concentrations would be at their highest. Indeed, this was found to be the case, with three-quarters of all specimens exhibiting this failure mode.

A small number of specimens failed prematurely due to the occurrence of splitting. The occurrence of splitting was investigated by increasing the edge distance between the bottom face of the specimen and the rod axis. An increase in edge distance of one bar diameter was found to reduce instances of splitting 
optimum value for edge distance for this set up.

\section{Acknowledgements}

This research was funded by the Department of Agriculture, Food and the Marine of the Republic of Ireland under the FIRM/RSF/COFORD scheme as part of 'Innovation in Irish Timber Usage' (project ref. 11/C/207).

\section{References}

[1] M. del Senno, M. Piazza, and R. Tomasi, "Axial glued-in steel timber joints experimental and numerical analysis," Holz als Roh- und Werkst., vol. 62, no. 2, pp. 137-146, Apr. 2004.

[2] R. Steiger, E. Gehri, and R. Widmann, "Pull-out strength of axially loaded steel rods bonded in glulam parallel to the grain," Mater. Struct., vol. Vol. 40, no. 8, p. p 69-78, Jan. 2006.

[3] K.-U. Schober, M. Jahreis, W. Haedicke, and K. Rautenstrauch, "Bonding behavior of nearsurface mounted and externally bonded CFRP strips and timber in the end-anchorage zone Part 1 : Small-size specimen testing and NDT measurement," in COST Action E34 Boding of Timber, Proceedings of the Final Workshop, 2008.

[4] B. H. Xu, A. Bouchaïr, and P. Racher, "Analytical study and finite element modelling of timber connections with glued-in rods in bending," Constr. Build. Mater., vol. Vol 34, pp. p337-345, 2012.

[5] B. Pizzo, M. Gavioli, and M. P. Lauriola, "Evaluation of a design approach to the on-site structural repair of decayed old timber end beams," Eng. Struct., vol. 48, pp. 611-622, 2013.

[6] M. Andreolli, M. Piazza, R. Tomasi, and R. Zandonini, "Ductile moment-resistant steel-timber connections,” Proc. Inst. Civ. Eng. - Struct. Build., vol. 164, no. 2, pp. 65-78, 2011.

[7] M. Vašek, "Semi rigid timber frame and space structure connections by glued-in rods," in Proceedings of the 10th world conference on timber engineering, 2006, pp. 539-547.

[8] R. Steiger, E. Serrano, M. Stepinac, V. Rajčić, C. O’Neill, D. McPolin, and R. Widmann, “Gluedin rods," in Reinforcement of Timber Structures - A state-of-the-art report (COST), A. Harte and P. Dietsch, Eds. Aachen: Shaker Verlag, 2015, p. 234.

[9] British Standards Institution, BS EN 408:2010+A1:2012 Timber structures. Structural timber and glued laminated timber. Determination of some physical and mechanical properties. London, England: BSI, 2012.

[10] British Standards Institution, BS EN 14358:2016 Timber structures - Calculation and verification of characteristic values. London, UK: BSI, 2016.

[11] G. Tharmarajah, "Compressive Membrane Action in Fibre Reinforced Polymer (FRP) Reinforced Concrete Slabs,” Queen's University Belfast, 2010. 
[12] Rotafix Ltd, Rotafix Structural Adhesive - Epoxy Bonding Adhesive. Data sheet, Swansea, UK, 2015.

[13] G. Tlustochowicz, E. Serrano, and R. Steiger, "State-of-the-art review on timber connections with glued-in steel rods," - Mater. Struct., vol. 44, no. 5, pp. 997-1020, 2011.

[14] RILEM TC, "RC 5 Bond test for reinforcement steel. 1. Beam test, 1982," in RILEM Recommendations for the Testing and Use of Constructions Materials, RILEM, Ed. E \& FN SPON, 1994, pp. 213-217.

[15] K. Harvey and M. P. Ansell, "Improved timber connections using bonded-in GFRP rods," in Proceedings of 6th World Conference on Timber Engineering, Whitsler, British Columbia, 2000.

[16] CEN, Design of timber structures. Part 2: bridges (Annex C: bonded-in steel rods, second draft). Brussels, Belgium: CEN, 2003.

[17] D. Yeboah, S. Taylor, D. McPolin, R. Gilfillan, and S. Gilbert, "Behaviour of joints with bondedin steel bars loaded parallel to the grain of timber elements," Constr. Build. Mater., vol. 25, no. 5, pp. 2312-2317, 2011.

[18] N. Gattesco and A. Gubana, "Experimental Tests on Glued Joints Under Axial Forces and Bending Moments," in PRO 22: Rilem Symposium on Joints in Timber Structures, 2000, p. pp353-362.

[19] J. G. Broughton and A. R. Hutchinson, "Pull-out behaviour of steel rods bonded into timber," Mater. Struct., vol. Vol 34, no. March, p. p 100-109, 2001.

[20] J. Sena-Cruz, J. Branco, M. Jorge, J. A. O. Barros, C. Silva, and V. M. C. F. Cunha, "Bond behavior between glulam and GFRP's by pullout tests," Compos. Part B Eng., vol. 43, no. 3, pp. 1045-1055, Apr. 2012.

[21] M. Stepinac, V. Rajcic, F. Hunger, J.-W. van de Kuilen, R. Tomasi, and E. Serrano, "Comparison of design rules for glued-in rods and design rule proposal for implementation in European standards," in CIB W18 Meeting Forty-six, 2013.

[22] Deutsches Institut für Normung e.V, DIN 1052. Entwurf, Berechnung und Bemessung von Holzbauwerken - Allgemeine Bemessungsregeln und Bemessungsregeln für den Hochbau. Berlin, Germany, 2008.

[23] H. Riberholt, "Glued bolts in glulam - proposals for CIB code 21-7-2," in Proceedings of the 21st conference of CIB W18, 1988, p. Paper 21-7-2.

[24] V. Gardelle and P. Morlier, "Geometric parameters which affect the short term resistance of an axially loaded glued-in rod," Mater. Struct., vol. 40, no. 1, pp. 127-138, Oct. 2006.

[25] D. Yeboah, S. Taylor, D. McPolin, and R. Gilfillan, "Pull-out behaviour of axially loaded basalt fibre reinforced polymer (BFRP) rods bonded parallel to the grain of glulam elements," Struct. Eng., vol. May, pp. p42-51, 2012. 